\title{
Performing Hypermasculinity in Billboard Ads and Malls in Manila
}

\author{
Gary Devilles
}

\begin{abstract}
Images of masculinities are used in ad placements in TV, movies, and billboards. Aside from the consumerist nature of such images, I wonder if these constitute city dynamics, such that life in the city can be construed as fantastical or spectacular, and whether such fantasy is masculine in orientation. This work investigates masculinity not just as a product of city living, but also as a phenomenon in which the city seemingly assumes a muscular stance, manifesting in its ensuing power relations. I focus on underwear billboards and malls in Manila as texts by which hypermasculinity, this male fantasy, is produced, performed, becomes visible. I also discuss Susan Bordo's assertion that the study of masculinity is in no way isolated from feminism. Through her account of her father's life, and analyses of advertisements and TV shows, she argues that male experiences of shame, exhaustion with cultural expectations, or the failure of the male body to live up to those expectations, resonate with the feminists' struggle for emancipation. In this light I approach masculinity and city studies as mutually inclusive fields, underlying a male fantasy, a hypermasculinity, which is all too visible, dominating and shaping our lives. Hypermasculinity feeds on the culture of consumption, the fetishism of masculine virility and objectification of women, on the panoply of images evoking beauty and nostalgia. I argue that the city-specifically Manila-being hypermasculine, hides its ugliness and shame, and its development is posturing, aggressive behaviour, compensating for irreconcilable contradictions and alienated relationships.
\end{abstract}

KEY WORDS: hypermasculinity, Manila, masculinity, popular culture, urban studies 
Gary Devilles, "Performing Hypermasculinity in Billboard Ads and Malls in Manila"

\section{THE FANTASY OF HYPERMASCULINITY}

As I write, Australia celebrates its Father's Day. All around Melbourne, restaurants, shopping malls, bookstores are selling gift items for fathers. Without a doubt there is capitalization of such sociality-various images of fatherhood become visible in ad placements on TV and in movies, evoking romantic feelings that taunt us into buying. However, aside from such a fantasy being a commodity, I wonder if this fantasy is constitutive of city dynamics, such that life in the city, along with its contradictions, can be construed as fantastical, phantasmic or spectacular. I am interested in whether such a fantasy is actually masculine in orientation. My concern is to investigate masculinity, not only as a product of city living, but also as a phenomenon in which the city seemingly assumes a muscular stance with its generative and ensuing power relations. It is interesting to see the city in terms of gender construction and body morphology, since issues and concerns about the body became more ubiquitous in the 1970s-which coincided with the urbanization of most cities across the world.

In that decade, there was a growing interest in and fascination with bodies, and with male bodies in particular. Male bodies were the subject not only of literature but almost fetishized in various forms of popular culture-from advertising, to sports, songs, melodramas, etc. The late $20^{\text {th }}$ century is said to be the height of investment in the body, when it has become the province of commodity-most notably in the fitness world. Bodybuilding's rise to mass appeal, for instance, can be dated to the award-winning film Pumping Iron, released in the mid-1970s, which in turn popularized fitness training, health clubs, supplements, dietary recommendations, and equipment (Klein 6-18).

In her book The Male Body, Susan Bordo looks at this problem not exclusively as a study of masculinity, but also as a way of understanding herself and feminism. Her touching, though brief, account of her father's life points to how she shares much with her father despite their differences, while her brilliant reading of popular culture (from Jockey ads, to a TV series like Ally McBeal, and the film, Boogie Nights) shows that certain male experiences of shame and exhaustion with cultural expectations, or experiences of failure of the male body to live up to those expectations, resonate with women's crises and their concomitant struggle for emancipation (3-35). It is in light of Bordo's work that I would like to approach masculinity and city studies, not as specific and autonomous areas of study, but rather as mutually inclusive fields, underlying a male fantasy that is all too visible and continues to shape our lives. I will examine 
various Philippine depictions of male bodies in Manila's billboard ads, buildings, and politics as evocative of this fantasy.

In Manila, the construction boom and city development coincided with the Marcos dictatorship, and his urban renewal programs were steeped in promoting Manila as the spectacular City of Man, with all its art and business centers and public housing. Marcos reclaimed and redesigned areas of the city while at the same time employing massive violent dispersals and relocations of squatters. This urban gentrification program involved a showing-off and concealment, highlighting buildings and monuments, while insidiously hiding the ugly-which in Manila's case, were the squatters, the informal housing of immigrants from the poorer regions and provinces.

Elsewhere in the world, we see the same phenomenon, such as the urbanization of Brazil that coincided with the alienation of its people, along with the rise of violence and notoriety of political figures. Berman recalls his encounter with Brasilia in 1987, the capital city created by Kubitschek, and planned by Costa and Niemeyer. He said that Brasilia looked dynamic and exciting, built to resemble the jet plane-and yet from the ground level, where people actually live and work, it was one of the most dismal cities in the world (6).

Brazil's urban development is not far from Manila, in terms of the contradiction of city living and the ambivalent attitude of those who live there-many of whom feel forced to live in Manila to earn a living. The situation is complicated further by the conscious hyperperformance and the excessive lifestyles of politicians and the elite, thus linking urban development with this male fantasy. Development in Manila can be understood within the context of virility-figuratively the "flexing of muscle" by these local and national despots, provincial warlords, and political clans whether in the Philippines, Bombay, Mexico, and Colombia (Sidel 1-18). As these cities are caught up in the pageantry of rapid development, the appearance of the city becomes more exaggerated and actually more hypermasculine. By "hypermasculine," I refer to a psychological pathology that feeds on aggression, determination, and energy to compensate for a lack of confidence or for irrational behaviour. The city, being hypermasculine, hides its ugliness and shame, and its development is a facade, a posturing, aggressive behaviour to compensate for its irreconcilable contradictions and alienated relationships.

In Manila, billboard ads and malls function to conceal ugliness and contradiction. Most of these billboards are stretched along Epifanio de los Santos Avenue or EDSA, the main arterial road and freeway in Metro Manila. It is composed of 12 lanes stretching 23.8 kilometers, connecting 
the cities of Caloocan, Quezon City, Mandaluyong, San Juan, Makati, and Pasay, and providing access to the cities of Taguig, Pasig, San Juan, and Parañaque. EDSA handles an average of 316,345 cars and 2.34 million vehicles every day.

Billboard sizes vary from 5-12 meters in height and 4-12 meters in width. A typical 5m x 4m billboard costs about Php15,000 (or AUD350) per month. The enormous sizes of billboards are designed to cater to both motorists and to passengers of the Manila Metro Rail Transit System (MRT), located above EDSA, with thirteen stations along its $16.95 \mathrm{~km}$ track. In 2004, it was recorded that MRT had a ridership of 400,000 passengers daily. With roughly 15 million people in Manila-many of whom ply EDSA daily-the billboards are an industry with a captive market.

It is not surprising, then, that billboards in Manila are quite a phenomenon in themselves, entailing a set of ways of experiencing the world, serving to legitimize dominance along with its ideological or discursive formation. It is in light of this billboard industry, its interesting display and depiction, and its concomitant reactions from passers-by and passengers, that I see hypermasculinity as a constructed fantasy that animates, if not determines, our complex sociality and political relations in the city. Billboards contribute largely to the range of images that the city envisions and tries to perform, revealing as well as concealing city life, creating patterns of power relations that are contestable and contested. Urbanization in the 1970s, and until the present, insofar as uneven development is concerned, manifested and imagined in billboard advertisements, is a male fantasy, a form of hypermasculinity of city visibility (Zizek 33).

\section{HYPERMASCULINITY AND HOMOPHOBIA IN ADVERTISEMENTS}

Last year, one Metro Manila mayor ordered the removal of a Bench Underwear billboard advertisement (fig.1) along EDSA. The ad featured the Philippine Rugby Team-also known as the Philippine Volcanoes-in their underwear. Eventually, the Ads Standards Council (ASC) took the billboards down, mainly because of the ad's focus on a man's crotch (or that "bulge" in a man's genital area), claiming that as an institution, they have always practiced self-regulation of ads that have images with sexual overtones or of models in suggestive poses. 


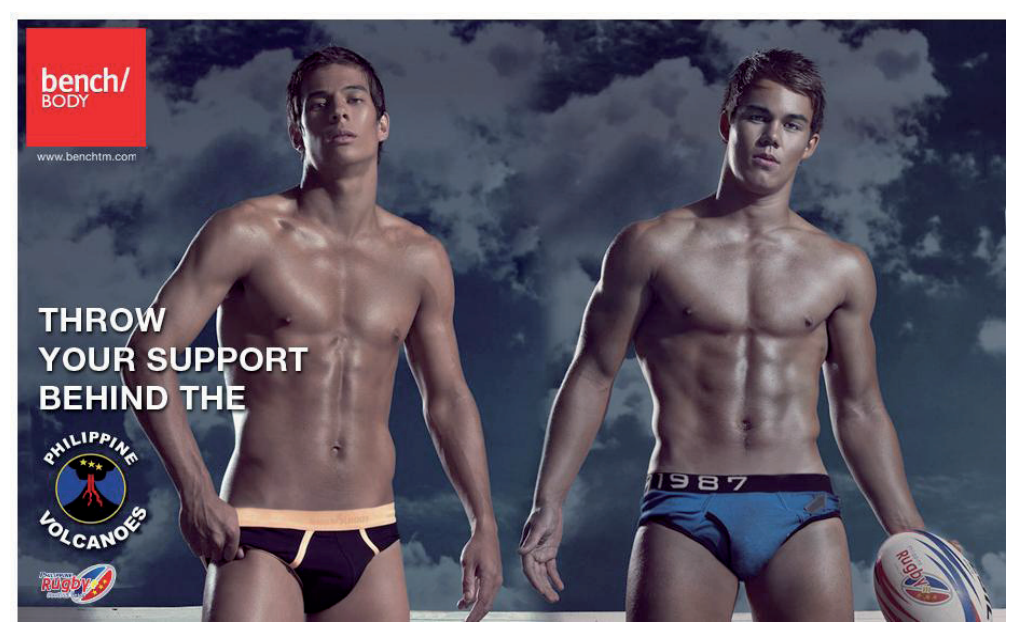

Fig. 1. Image of Bench Body billboard advertisement from Tyrell; "The Volcanoes Model Body by Bench"; Homorazzi.com, 2011; Web; 2 Feb. 2013.

Censorship or regulation of such billboard ads brings to the fore the ambivalence towards the male body, regardless of whether this is from people who claim higher moral ground, or from a kind of society that identifies itself with a particular interest or principle of exclusion. The ruckus over the billboards already reveals who and what we are, and the comments it generated from the public in newspapers and on the internet are indicative of our conflicts and struggles. The mayor's disgust over the images, and the comments about the mayor's reaction, also show how little we know about ourselves.

For instance, one would expect that in a modern city like Manila, we would have no qualms about the exposure of bodies, as Manila is not so different from other cities with Jockey and Calvin Klein billboards, featuring famous people like Mark Wahlberg and David Beckham in their underwear. One disappointed blogger commented, "Asan na ba tayo? Manila ba o bundok?" (Where are we? In Manila or on a mountain?). The reference to a mountain is a rejection of antiquated, provincial mentality, and expresses the expectation that Manila is a place for progressive and open-minded people. While the blogger's comment reveals a particular self-understanding of inhabitants of cities, his frustration on the whole is also a critique of censorship. Another blogger's comment was about living in a bygone era, that ad censorship is anachronistic. These comments re- 
veal a fascinating incongruence over what we assume to be modern living versus our more traditional and conservative mode of life.

Aside from this divide over what constitutes modernity against conservatism and traditionalism, another comment shows different aspect of this fracture, this incongruity, highlighting the divide between disgust with male nakedness against predilection of women's bodies. The blogger posted, "How come the billboard ad on women's underwear which is exactly just beside it were not asked to be torn down?" (sic). The comment points directly to the contradiction of disgust, in so far as disgust frames our selective attraction and implicates the male fantasy that objectifies women's bodies. Dollimore pointed out that disgust always bears the imprint of desire, and that it is here that aversion can sometimes be played as fantasy (54-56).

The whole narrative, therefore, of public outcry about the "immorality" of the billboard in question-and even the tweet of another mayor in Manila who said that he can now pass EDSA without worrying about his children's exposure to indecency-is an elaborate male fantasy, a fantasy that needs to be understood in relation to city dynamics. What is the fuss all about? When one makes an argument about morality and decency of ads at this time, what is the relationship between it and the disciplinary action that censors such ads? Why is it that people see nothing wrong with the objectification of women's bodies but become anxious about male nakedness?

These questions point to the male fantasy as effected by an exercise of power. As a fantasy, what is revealed is not just the body of the condemned in the Foucauldian sense, but also the gaze that subjects the body, the gaze that optimizes the sight, manipulates visibility, reveals, conceals, and controls. For instance, Barthes believes that wrestling is not really a sport but a spectacle that works under the rubrics of theatricality, and people watch wrestling based on their expectation of a tragic narrative, who is considered blasé and evil, how evil will be defeated and conquered, how justice will be dispensed, etc. Hence, it is not important whether wrestling is true or not, what matters is its faithfulness to a universal drama, to a fantasy (Barthes 8-9). Likewise, censorship is not about morality, but about whether something is considered appropriate or inappropriate, pleasant or abominable in the context of the fantasy. 


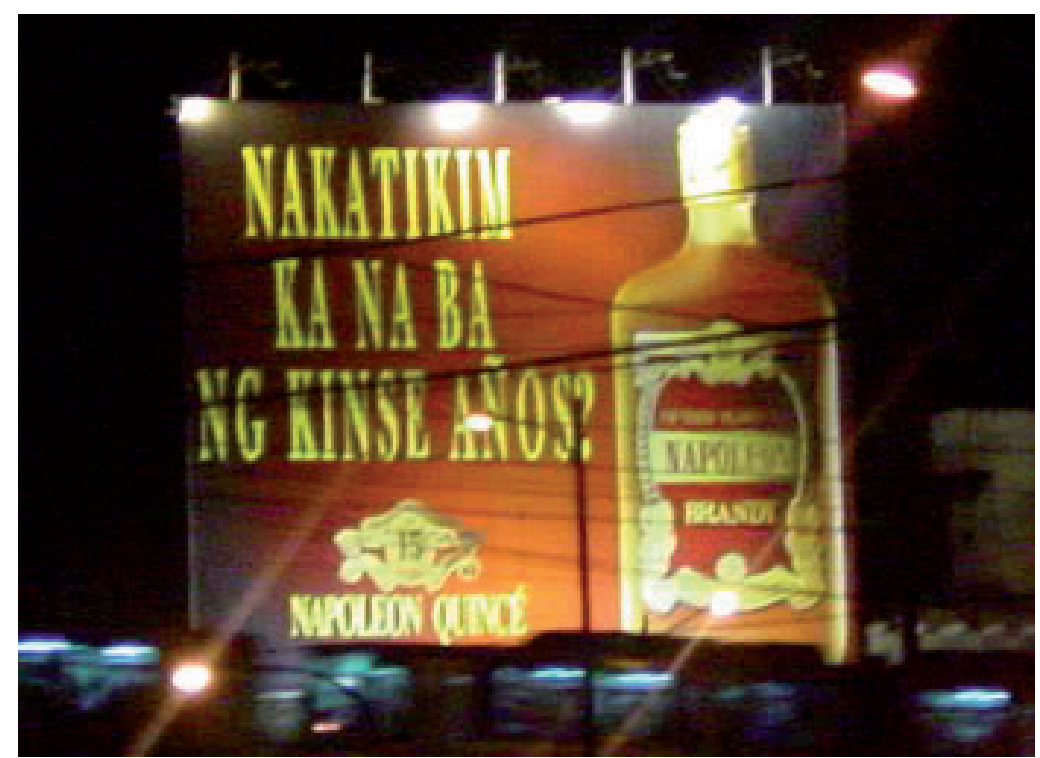

Fig. 2. Photograph of billboard by J. Sotto; "Brandy ads fire up intense public rage”; PRWeek.com, 2004; Web; 2 Feb. 2013.

Actually, this is not the first incident in Manila when billboard ads caused so much controversy. In 2005, there was controversy about the billboard ads of Napoleon Brandy Quincé (fig.2). The ad shows no naked women, just the bottle of brandy itself, with the caption, "Nakatikim ka na ba ng kinse anyos?" ("Have you tasted a 15-year old?"). The billboard was also displayed along EDSA and caused a lot of furor among the public because of the double-entendre of the caption-ostensibly about the brandy being aged 15 years, while alluding to young prostitutes, who are usually 15 years old. The controversy went to court and the court acknowledged the problematic caption and ordered the company to pull down its billboard. But soon after the court order, the same company came out with a billboard that was even more denotative (fig.3). This time there were images of men drinking, and instead of using the interrogative sense of the original caption, they used the declarative sense, "Nakatikim na sila!" ("They've already tasted it!"). Although this version is much more forthcoming, it is more blatant with its exhibition of male prowess and fantasy, using four ordinary-looking, middle-aged, working-class men drinking the brandy. 


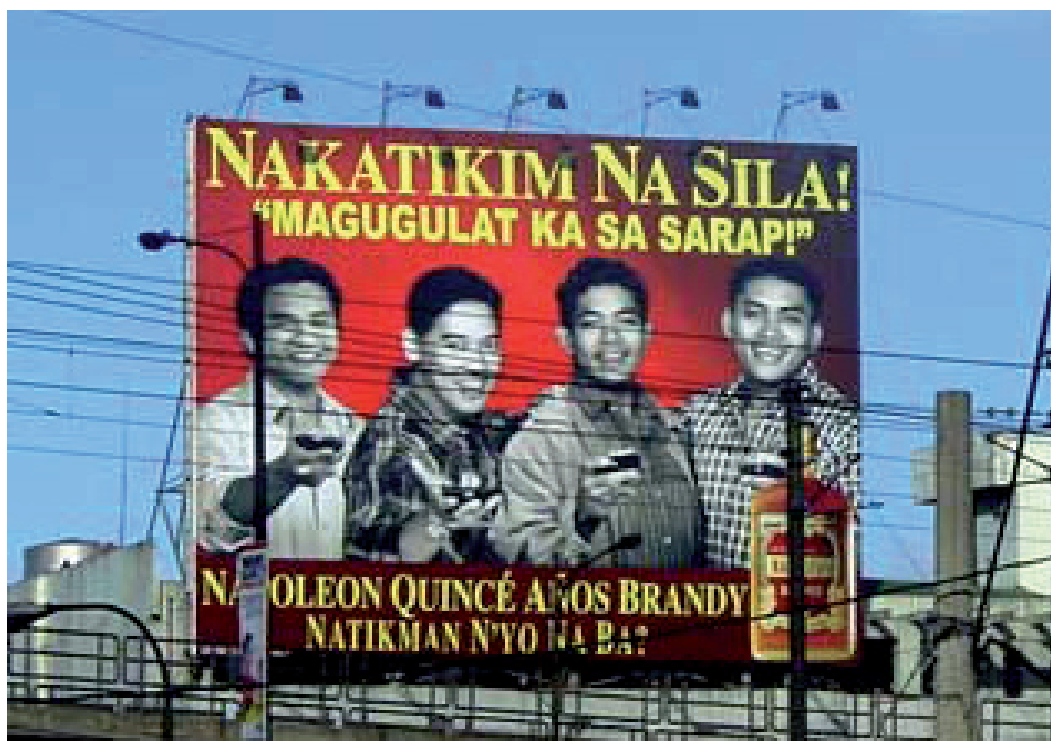

Fig. 3. Photograph of billboard by C. Tejada; "Nakatikim ka na ba ng Kinse anyos?”; caratejada.multiply.com, 2005; Web; 2 Feb. 2013.

What must be noted here in these billboard ads is that male fantasy does not necessarily employ images in their objectification of women. A seemingly innocent caption can actually be an exhibition of power, and the drama that ensues can be simply its extended and intended narrativization. The censorship of the Bench Underwear billboard, therefore, can be construed as emplotment in which the public aversion is either an implicit homophobia or a reaction to a competitive threat versus traditional masculinity. The Bench Underwear ad shows two naked guys with a backdrop of the blue sky suggesting a romantic, leisurely, laid-back mood, and a caption that reads "throw your support behind the," followed by their team's logo. The advertising copy is actually suggestive of touching their behinds, partly revealed by their underwear. In some of the ads, the posture of the athlete is really orchestrated to achieve such an effect. There is nothing new about this sexual innuendo, since most ads capitalize on sex and sexuality, but the homoeroticism in this ad is strong enough to ruffle undoubtedly even the most alleged macho man, in this case, the politician or the mayor.

Compared to the Napoleon Brandy ad, in which men were depicted as hardworking and fully clothed, the two naked guys of Bench must be seen as their opposite or their anti-thesis. If these macho men, like the mayor, 
fancy themselves to be strong and real men, then the Bench models are images of the weaker other, the homosexual, etc., and such images should be repudiated, albeit theatrically. There should be a public condemnation of such images, a spectacle of tearing down; a narrative of the father who feels the world is unsafe for his children; and a melodrama which could include religious groups rallying against ad agencies, which in turn invoke their freedom of expression. Censorship plays and feeds on this fantasy which has always been at the patriarchy's disposal. No need to scream, just speak softly and carry a big stick, as the saying goes-and one has secured this male power.

The mayor and, to a certain extent, some conservative groups, play their part well, including the advertisers who willingly take down their billboard. This irrational fear of homoeroticism and sexual perversion reminds us of Freud's concept of Eros and Civilization, where he explains that to gain a semblance of political maturity, one has to renounce the instinctual erotic, the upper body rejecting the lower part, the superego against the id, enlightenment over our anal stage of development. The anxiety over male nakedness is really the male fantasy that cannot see itself, nor project itself, as base and erotic. It is a male fantasy that constantly wants to see itself as powerful, rational, and overcoming its weaknesses. Thus, the caption, throw your support behind the, somehow reiterates this anxiety that bifurcates into homophobia and heteronormativity, and censorship becomes its closure and logical denouement. However, one should also take into consideration that homophobia need not be construed only as a repression since it can also work in a terrifying mutability of desires, where abhorrence becomes desirability or repugnance swings to attraction (Dollimore 56). In other words, the fear of naked male bodies can also be an expression of the desire for, or attraction to, that kind of body, and to homosociality.

By comparing these men in the Bench Underwear and Napoleon Quincé Brandy ads, one can note not only the difference in terms of nakedness, the laid-back youth over the more mature working men, but also that the models for Bench are mostly Filipino-Americans, who are more fashionable, more marketable, and more desirable to men and women alike. The image and kind of masculinity of Filipino-Americans is a threat to the traditional Filipino image of masculinity. Such anxiety can also be related to the prevailing economic conditions, where there is a growing feminization of both the domestic and overseas labor market. As more and more Filipino women work, especially overseas, and their husbands are left to do the household chores and care for children, the Bench ad's 
use of Filipino-Americans only reinforces the emasculation of traditional Filipino masculinity.

The popularity of Filipino-American models can be considered a displacement of the traditional Filipino male fantasy. Back in the early 1980s, the masculinity of Filipino-Americans (or Filipino-Caucasians) has always been suspect and ridiculed. They were called coños-from the Spanish word for vagina, the female sexual organ-a derogatory term showing how they were considered more feminine than masculine. But with the advent of metrosexuality (that is, a heterosexual living in a metropolitan area, who spends a lot of time and money on shopping for beauty products and clothes), the androgynous character of Filipino-Americans lent themselves as perfect models for these advertisements. The popularity of Filipino-American images parallel David Beckham's rise to fame as football player and metrosexual, and his endorsements of perfumes and underwear (fig.4). Hence, the overwhelming reception to Filipino Americans on TV, advertisements and cinemas signals a shift to this new image of masculinity, this new desire and fantasy.

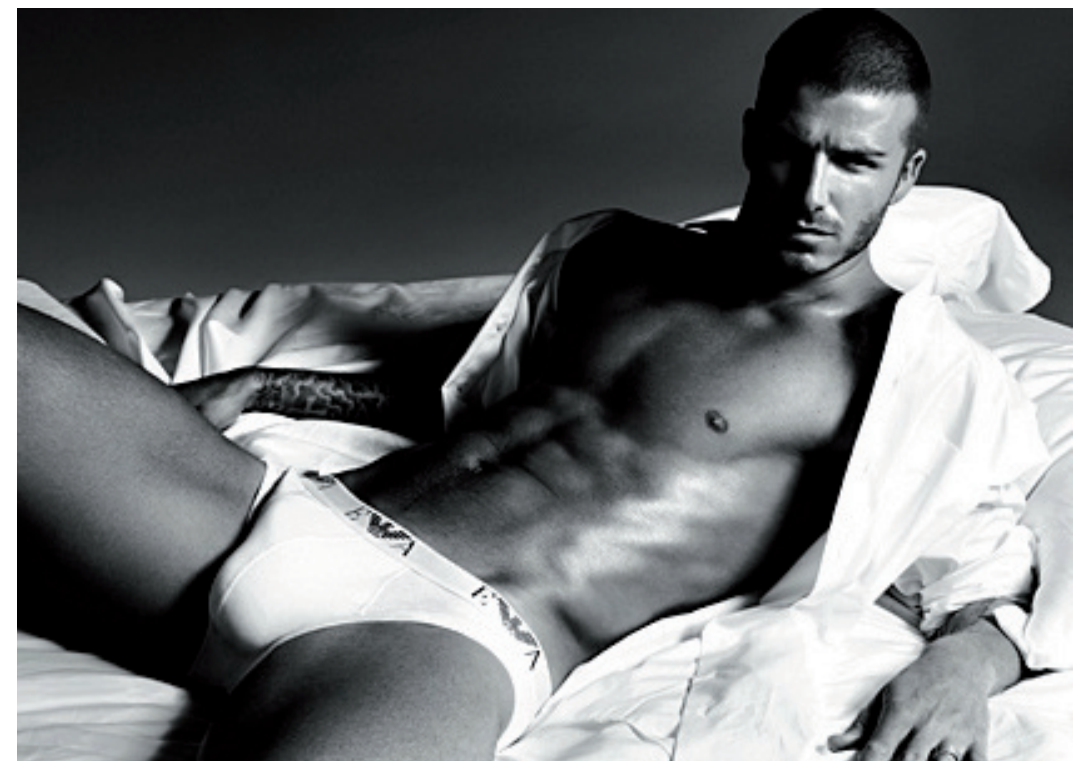

Fig. 4. Image of David Beckham in an Armani advertisement;

"David Beckham shows off Golden-bulge in Armani ad"; The Daily Telegraph, 2007; Web; 2 Feb. 2013. 
Lastly, one should also note that these Filipino-American athletes in the Bench Underwear ads are rugby players, who do not represent the more popular and (for Filipinos) the more "macho" sport of basketball. The growing popularity of football and the growing demise of basketball in the Philippine sports industry is another symptom of this hypermasculinity, the competition of masculinities, the struggle for power and attention of these two different male fanstasies.

The spectacle that was the Bench billboard ad reveals the confluence of sports, politics, language, and class conflicts that are embroiled in unspoken homophobia and desire of the new Filipino masculinity. For Debord, at the root of a spectacle lies the oldest of all social divisions of labor, the specialization of power; and here in this billboard, what we see is the visible manifestation of hypermasculinity, the pervasive patriarchal fantasy as ancient as when cave men beat their breasts to attract females and rule over other men (18-19). These giant billboard ads are placed strategically along highways and, in so doing, conceal and mask the city from train and car passengers, giving the illusion of progress, a deceptive vision of our real conditions. The background of infinite blue sky in the Bench billboard (fig.5) is meant to blur the borders of its frame, seemingly replacing the real horizon, and warping us into timelessness, the end of history, and to our unattainable desires. With such bombastic fantasy we relinquish our critical mindset and lapse into perpetual numbness. Obviously, the billboard ads are only one of the many instances by which hypermasculinity manifests itself, as in the 1970s when the Marcos regime used hypermasculinity to control the populace and impose Martial Law.

\section{HYPERMASCULINITY IN MALLS}

Lico's comprehensive and exceptional study of Philippine architecture frames our study of city hypermasculinity. In his book Edifice Complex: Power, Myth and Marcos State Architecture, he contextualized the history of Philippine architecture as a series of non-coercive impositions of power, from the colonizers leading up to Marcos's regime in the 1970s, through stone, concrete, and glass. He asserts that "architecture and urban design are deeply ingrained within economic and other structures of power, the very physicality of architecture maintains the power and status quo of its patron" (157). He cites various projects of the Marcoses, like the Cultural Center of the Philippines, Philippine International Convention Center, Philippine Heart Center, and Coconut Palace, as symptoms of the couples' neurotic fixation with projecting themselves as saviors, bearers of 
enlightenment, embodiments of strength and beauty, etc. Indeed, the excesses of the Marcoses were apparent not only in various arts and cultural programs they enacted but also in the buildings themselves. Lico called this an edifice complex, that is, a strong obsession to erect monuments or buildings that will signify power and give that effect of surveillance and control. The buildings and monuments function not only as public spaces. In their grandiosity, one cannot help but be awestruck and, in the process, a certain amnesia is induced, in which one forgets the hard labor and the enormous funding that went into these buildings and monuments.

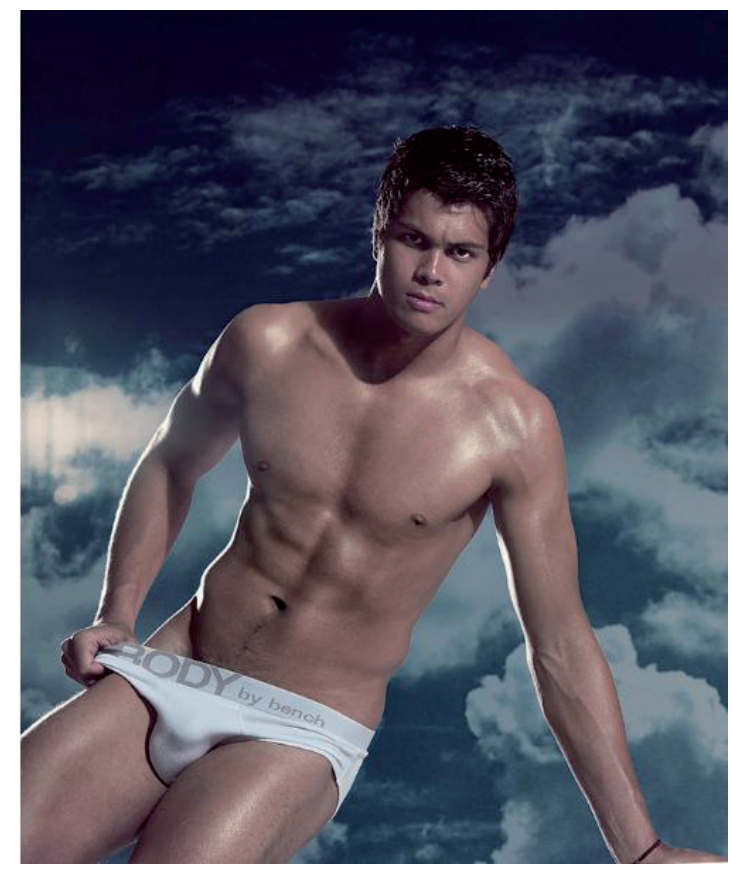

Fig. 5. Image of Bench Body advertisement by Tyrell; "The Volcanoes Model Body by Bench"; Homorazzi.com, 2011; Web; 2 Feb. 2013.

Like the billboard ads, these buildings show a deceptive vision of our social realities. Contrary to expectation that such monuments or buildings bring about nascent modernity, they are instead stark and palpable reminders of brutality and the continuing domination and alienation of man. Although some of these buildings are already condemned, they continue to haunt us and the vestiges of edifice complex are still operative and multifarious. It is in this context that the hypermasculinity of the city 
can also be understood, primarily as a fantasy that assumes architectural forms, and secondly as perpetuating fantasy that weighs on our perception and experience of city living.

Walter Benjamin's reflection on arcades tells us that myths pervade city living, and that modernity, together with all the technological advances and instrumentalism, is really a manifestation of a new age of illusion, ignorance, and barbarism (Gilloch 9-13). In so far as the Marcoses fostered the illusion of progress in the 1970s through dictatorship and the beautification of Manila, one should also note how such illusion or fantasy is continually being performed and experienced today through the Filipino leisure culture and the expansion and proliferation of malls.

One of the early Metro Manila malls, Megamall, was built in 1989 in Mandaluyong City. It stands along the main EDSA thoroughfare and is almost adjacent to the Manila Metro Rail Transit (MRT) Ortigas station. SM Megamall was the largest mall in the country for a long time, but when SM Mall of Asia was built, Megamall became the third largest in the country by floor area. Its immensity can be seen as a trickle effect of the Marcosian edifice complex; however, its exterior is not as elaborate as buildings made during the Marcos era, since the building looks like a shoe box, alluding to its humble beginning as a shoe store. What is compelling about Megamall is the interior and the way it has produced spectacles within. The moment you walk into the mall, you are bombarded with advertising images, rows of stores with their own display windows, and, of course, being in a sultry country, the welcome respite of air-conditioning.

What is happening in a mall is an ensemble of fantasy production that primarily makes you forget time. The mall replicates streets and parks where people can walk leisurely and feel safe without having the anxieties of being run over by vehicles or being victimized by street criminals. The concrete walls prevent anyone from seeing the outside. So, as one walks from one end to another, awestruck by all the display windows, it is possible for one to lose sense of time. Moreover, since there are very few benches, it becomes virtually impossible for people to stop walking unless they go to the mall's restaurants, cinemas, or stores. The toilets are strategically placed at the opposite ends of the mall, guaranteeing continuous lateral traffic of shoppers. Each floor is also designed in such a way that the busiest floors-like the food court and cinemas-are at the basement and higher levels, also ensuring a vertical flow of mall goers.

Inside the mall is a multi-floor department store. Each floor is tailor-fit for gender differences. Since women tend to spend more time shopping, most of their changing stalls and products are placed at the second or 
third floors, while those for men tend to be at the first floor. It is also important that the children's section-including toys and their clothes-are located at the third floor as well. Since children are normally accompanied by their parents, then the children's department placement on the third floor guarantees people's upward movement through the store.

The mall is one big, efficient machine that is capable on the one hand of producing fantasy, and on the other, reproducing the consumers of such fantasy. In billboards, fantasy is actually framed-the moment it disappears from view one forgets the fantasy. But in malls, fantasy is interiorized and internalized, and shoppers must be contained for enough time so that they become instant consumers. To ensure that these shoppers linger, it is necessary therefore to bombard them with spectacles and amusements, through events such as free concerts and promotional tours of popular actors.

Recently, malls in Manila have become even more aggressive in containing all the necessary activities of people. Inside the malls, chapels are built, as well as health and medical facilities, gyms, and even day care centers. One can imagine that a typical family day for Filipinos-from going to church, eating, watching movies, getting a medical check-up, and getting groceries-can all be done in one mall. Coffee shops in malls are popular as well, since they provide the needed space for some short office work; and with free wi-fi, customers can email, chat, and download files.

Lately, the owners of these giant malls have ventured into real estate development and banking. Most of their condominiums have their groceries and banks on the first floor, and often these condominiums are located near malls as well. Such keen business strategies are not just about selling of merchandise; these strategies are meant to reproduce the consumers within the vicinity and to contain them there as much as they can. The immensity of malls in Manila is not just replicating fantasy but replicating the whole fantasy of city living. In fact, many malls are (aptly) named SM City (fig.6).

Since these malls are also connected to the trains that ply EDSA, the whole of Manila is connected by these malls as station stops. They virtually become the pulse of city living, and, as the crowds go to work then head home, they have also become convenient terminals for taxi cabs, buses, and other forms of public transportation.

With other competing malls like Greenbelt, Glorietta, Robinsons Galleria, malls also replicate segregation or selective and target marketing. Some malls, like Greenbelt and Shangri-la Mall, are designed to cater to the $A B$ crowd, while others, like Glorietta and Market Market, are more for the CD crowd. In Megamall, there is the Atrium, while SM City North 
EDSA has The Block, catering to more well-off consumers. This culture of segregation is not really far from the kind of socio-political segregation that happened when the old Manila, Intramuros, was built, with the walls literally and figuratively excluding those of a lower social class.

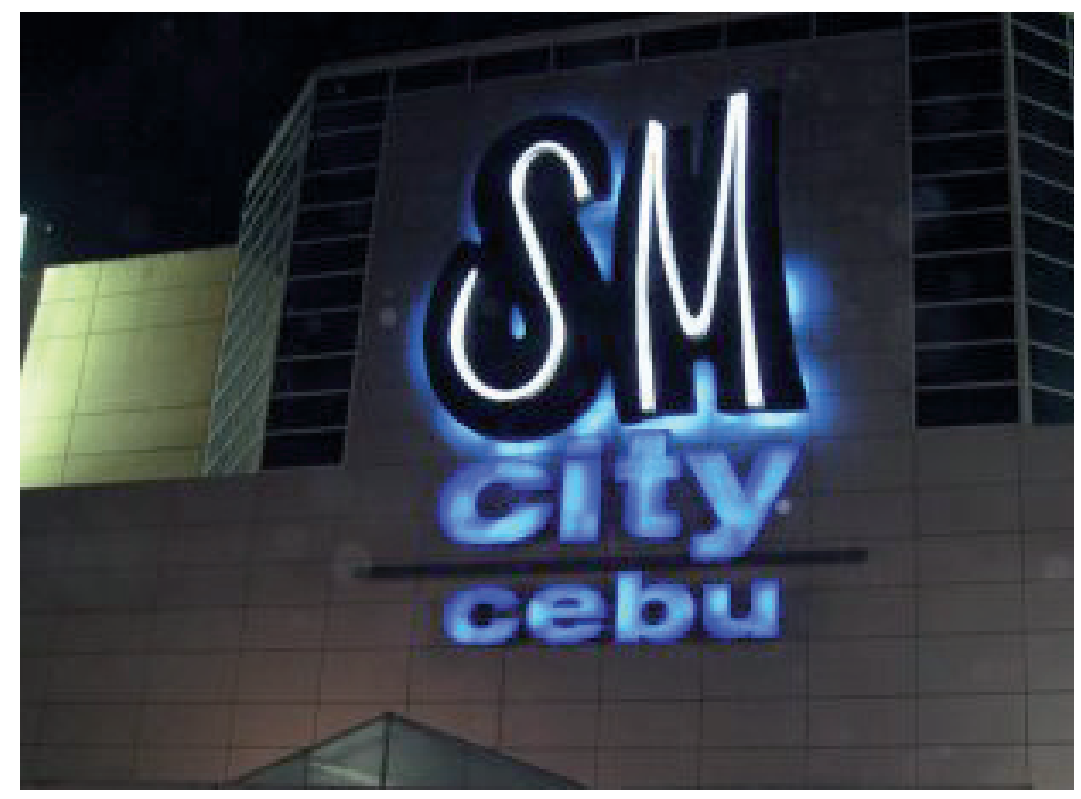

Fig. 6. Photograph of SM City Cebu's façade. SMSupermalls.com, n.d.; Web; 2 Feb. 2013.

It is the same fantasy of the city, predicated on identification, control, and surveillance, which ultimately makes the fantasy a myth that Benjamin calls the myth of domination (Gilloch 13-15). In the myth of domination, the fantasy of the city takes on a very masculine, even hypermasculine, stature, in which everyone must submit reason to the blind, uncontrollable forces of market; hence, the enormous quantities of goods and commodities that surround us, ensnaring both the unwary and ardent consumers in us. Hypermasculinity enthralls us in the same way consumerism does, and we subscribe to it by way of spending our hard-earned money towards its attainment, or, at the very least, by longing for it.

In the process, the fantasy mystifies our social existence, and we become the very commodities that we covet either by way of accumulation of these goods or their deprivation. We define ourselves in terms of product labels and specifications-classifying our skin as oily or dry, our 
hair as naturally curly or straight. We think we gain freedom with the ability to choose, but the choices are actually, from the onset, determined by the market. Our identifications are determined by market research and surveillance in order to maximize profit, and this goes hand in hand with technology. With new gadgets, such as our mobile phones, there is that keen desire to personalize these with wallpaper, personal information, friends, favorite games, and music. There is always that strong feeling of loss when these gadgets are lost, stolen, or hacked. Some people even have an eerie feeling that part of their life is missing.

Our continued subjugation to this male fantasy or myth of hypermasculinity, to this edifice complex, to the cult of the primeval strong man that sees everything under control, to consumerism, only shows that we have not really freed ourselves from nature and necessity. Our mall culture proves otherwise-that we are continually trying to perfect this machinery of production and reproduction. Marx has said that we have endowed commodities with an aura power; in the same way, we have fetishized these malls and technologies. The end result is fatigue, withdrawal, and neuroses, hence the boredom, ennui, or existential angst. We become one of the many, indistinguishable, uninteresting, a copy. Despite the promise of renewal, instant rewards, and personal satisfaction, emptiness, nostalgia, and anxiety creep into our innermost being.

Hypermasculinity in the city is about the survival of the fittest and the cult of inequality. In the end, the malls produce a crowd where everyone is the same, moving with the same fluctuations, dreaming and half-believing in a world outside the giant concrete block they mistakenly believe holds everything for them. Benjamin reflects on this same emptiness and alienation, and ponders on these images in The Arcades Project, viewing them as forms of Freudian wish-fulfillment, like the Baudrillarian simulacra that not only mask a profound reality but bears no relation to any reality at all, a complete isolation that produces pure nostalgia:

These images are wish images, in them the collective seeks both to overcome and to transfigure the immaturity of the social product and the inadequacies in the social organization of production ... what emerges is the resolute effort to distance oneself from all that is antiquated. (Benjamin 33)

Such isolation is not the type of distancing that leads to self-reflexivity or to the transcendence of historic conflict between capital and the proletariat-consumers. Rather, the panoply of images evoke a simulated real life, convincing us that there is a "real" life, a world that is remade 
based on capitalists' desires; and no satisfactory strategies exist for overturning the proliferation of these images, this hyperreality, this hypermasculinity (Baudrillard 6).

\section{WORKS CITED}

Barthes, Roland. Mythologies. Trans. Annette Lavers. New York: Vintage, 2009. Print. Baudrillard, Jean. Simulacra and Simulation. Trans. Sheila Faria Glaser. Ann Arbor, MI: U of Michigan P, 1999. Print.

Benjamin, Walter. The Arcades Project. Ed. Rolf Tiedemann. Trans. Howard Eiland and Kevin McLaughlin. Cambridge, MA: Belknap P of Harvard UP, 1999. Print.

Berman, Marshall. All that is Solid Melts into Air: The Experience of Modernity. New York: Simon and Schuster, 1982. Print.

Bordo, Susan. The Male Body: A New Look at Men in Public and in Private. New York: Farrar, Straus and Giroux, 1999. Print.

Debord, Guy. The Society of the Spectacle. Trans. Donald Nicholson Smith. New York: Zone, 1995. Print.

Dollimore, Jonathan. Sex, Literature and Censorship. Cambridge: Polity, 2001. Print.

Gilloch, Graeme. Myth and Metropolis: Walter Benjamin and the City. Cambridge: Polity, 1996. Print.

Klein, Alan M. Little Big Men: Bodybuilding Subculture and Gender Construction. New York: SUNY P, 1993. Print.

Lico, Gerard. Edifice Complex: Power, Myth and Marcos State Architecture. Quezon City: Ateneo de Manila UP, 2003. Print.

Sidel, John. Capital, Coercion, and Crime: Bossism in the Philippines. Palo Alto, CA: Stanford UP, 1999. Print.

Zizek, Slavoj. The Sublime Object of Ideology. London and New York: Verso, 1989. Print.

Gary Devilles is an Assistant Professor at Ateneo de Manila University, and writes arts and book reviews for Philippine Daily Inquirer, Manila Times, and Metro Magazine. He is currently taking his postgraduate studies in Media Studies at La Trobe University (Australia). 